\title{
EFEKTIFITAS PROBLEM BASED LEARNING PADA MATERI LARUTAN ELEKTROLIT DAN NON ELEKTROLIT
}

\author{
Henni Fitriani \\ Fakultas Teknik, Universitas Malikussaleh \\ e-mail: henni.fitriani@unimal.ac.id
}

\begin{abstract}
Abstrak: Penelitian ini bertujuan untuk mendeskripsikan efektivitas Problem Based Learning terhadap aktivitas belajar peserta didik dalam proses pembelajaran pada materi Elektrolit dan Non Elektrolit. Penelitian ini dilaksanakan pada semester ganjil tahun pelajaran 2019/2020 di Program Studi Pendidikan Kimia Universitas Malikussaleh dengan sampel 20 mahasiswa yang diambil dengan teknik purposive sampling. Instrumen yang digunakan dalam penelitian ini adalah lembar observasi aktivitas peserta didik yang memuat karakteristik dari Model pembelajran PBL. Teknik analisis data menggunakan rumus deskriptif persentase. Data hasil penelitian menunjukkan jumlah rata-rata persentase aktivitas peserta didik yang tinggi dengan menggunakan Problem Based Learning yaitu mencapai $87,49 \%$.
\end{abstract}

\section{Kata Kunci: PBL, Aktivitas Peserta Didik, Elektrolit dan Non Elektrolit \\ PROBLEM BASED LEARNING EFFECTIVENESS ON MATERIALS ELECTROLYTE AND NON-ELECTROLYTE SOLUTIONS}

\begin{abstract}
Abstrak: This study aimed to describe the effectiveness of Problem Based Learning on student learning activities in the learning process on Electrolyte and Non-Electrolyte material. This research was conducted in the odd semester of the 2019/2020 academic year at the Chemistry Education Study Program, Malikussaleh University with a sample of 20 students who were taken using a purposive sampling technique. The instrument used in this study was a student activity observation sheet that contained the characteristics of the PBL learning model. The data analysis technique used a descriptive percentage formula. The research data shows that the average percentage of student activity is high using Problem Based Learning, which is $87.49 \%$.
\end{abstract}

\section{Kata Kunci: PBL, Student Activities, Electrolytes and Non-Electrolytes}

\section{PENDAHULUAN}

Pendidikan merupakan perubahan perilaku individu untuk menjadi individu yang lebih baik, sehingga pendidikan membantu manusia dalam mengembangkan potensi dalam dirinya hingga mampu menghadapi segala bentuk perubahan yang akan terjadi, oleh karena itu pendidikan menjadi faktor penting dalam menentukan kemajuan suatu bangsa (Efendhi dkk, 2014; Trianto 2009). Pendidikan yang baik merupakan pendidikan yang berkonsep pada penciptaan sumber daya manusia yang berdasarkan pemahaman nilai-nilai dalam kehidupan dan berkesinambungan, sehingga pendidikan dapat dikatakan berhasil jika seseorang dapat mengembangkan potensi yang ada dalam dirinya untuk menghadapi dan memecahkan masalah yang akan dihadapinya (Yusuf, 2009; Hartoto, 2016). Dalam pelaksanaannya, pendidikan diartikan sebagai usaha sadar dan 
terencana untuk mewujudkan suasana belajar dan proses pembelajaran agar peserta didik secara aktif mengembangkan potensi dirinya

Proses pembelajaran merupakan keterpaduan proses belajar dan mengajar. Proses pembelajaran yang terjadi di dalam kelas merupakan inti dari proses pendidikan, sehingga perbaikan mutu harus dimulai dengan menata dan meningkatkan mutu pembelajaran di kelas, mengembangkan aktivitas dan kreatifitasnya melalui berbagai interaksi dan pengalaman belajarnya agar dapat menunjang keberhasilan pembelajaran (Aldianur dkk, 2020; Sumarni dkk, 2017). Suatu pembelajaran dikatakan berhasil apabila tercapainya tujuan dari pembelajaran itu sendiri (Pane, 2017). Pada hakekatnya suatu pembelajaran haruslah menggunakan media dan model pembelajaran yang inovatif dan sesuai dengan kondisi kelas, sehingga mampu meningkatkan minat, aktivitas dan kreativitas peserta didik dalam pembelajaran (Indayatmi, 2017; E. Sutarno \& Mukhidin, 2013).

Pembelajaran kimia merupakan salah satu materi pembelajaran yang dianggap sulit oleh peserta didik, hal ini dikarenakan materi pembelajaran kimia bersifat abstrak dan konkrit. Ilmu kimia itu sendiri adalah salah satu rumpun IPA yang memiliki karakteristik saintifik dan empirik yang berasal dari kegiatan eksperimental di laboratorium. Pembelajaran kimia tentunya kurang tepat jika hanya memperhatikan produk tanpa mempedulikan proses yang berlangsung dalam setiap proses pembelajaran (Fitriani, 2017). Salah satu materi pembelajaran kimia yang harus dibarengi dengan kegiatan eksperimental dan menuntut pembuktian atas teori pembelajaran adalah materi larutan elektrolit dan non elektrolit. Dengan demikian peserta didik dituntut untuk lebih aktif dalam proses pembelajran tersebut hal ini di sebabkan keaktifan peserta didik mempunyai peran penting dalam pencapaian tujuan pembelajaran.

Salah satu model pembelajaran yang dapat meningkatkan aktifitas peserta didik adalah Problem Based Learning, dimana Model Pembelajaran tersebut mengadopsi pendekatan saintifik didalamnya. Peserta didik belajar tentang subjek melalui pengalaman pemecahan masalah. Esensi Problem Based Learning menyuguhkan berbagai situasi bermasalah yang autentik dan bermakna kepada peserta didik, yang dapat berfungsi sebagai batu loncatan untuk investigasi dan penyelidikan (Ariyanti dkk, 2015; Dewi dkk. 2017; Langit dkk. 2018; Widaningsih, 2018). Dalam hal ini model Problem Based Learning.

\section{METODE PENELITIAN}

Penelitian ini merupakan jenis penelitian deskriptif kualitatif yang dilaksanakan di Universitas Malikussaleh pada Semester Ganjil Tahun Pelajaran 2019/2020. Populasi dalam penelitian ini adalah seluruh mahasiswa Program Studi Pendidikan Kimia Universitas Malikussaleh dan sampel dalam dalam penelitian ini adalah mahasiswa pendidikan kimia semester 3 yang mengikuti perkuliahan Kimia Larutan sebanyak 20 mahasiswa yang terdiri dari 17 Mahasiswa perempuan dan 3 mahasiswa laki-laki yang diambil dengan teknik purposive sampling. Instrumen yang digunakan dalam penelitian ini adalah lembar observasi aktivitas peserta didik terhadap penerapan Problem Based Learning. Teknik analisis data menggunakan rumus deskriptif persentase untuk melihat hasil aktivitas peserta didik dengan rumus:

$\mathrm{P}=\frac{\left(\sum \text { Skor }\right) / 2}{\sum \text { Skor Total }} \times 100 \%$ (Sudjana, 2005) 


\section{HASIL DAN PEMBAHASAN}

Proses pembelajaran dengan Problem Based Learning pada materi pelajaran Elektrolit dan Non Elektrolit dilaksanakan dengan 2 kali pertemuan. Pengamatan aktivitas peserta didik selama proses pembelajaran berlangsung dilakukan oleh 2 orang pengamat. Data yang diperoleh dari hasil pengamatan dinyatakan dalam persentase, berikut data hasil pengamatan selama proses pmbelajaran berlangsung:

Tabel 1. Data Hasil Pengamatan Aktivitas Peserta Didik

$$
\% \text { Frekuensi Aktivitas Peserta Didik }
$$

Aspek Pengamatan

Pertemuan $1 \quad$ Pertemuan 2

\begin{tabular}{|c|c|c|c|c|c|c|c|c|c|c|c|c|c|c|}
\hline \multirow[t]{2}{*}{ Aspek Pen } & \multicolumn{3}{|c|}{ Pengamat 1} & \multicolumn{3}{|c|}{ Pengamat 2} & \multicolumn{4}{|c|}{ Pengamat 1} & \multicolumn{4}{|c|}{ Pengamat 2} \\
\hline & 1 & 2 & 34 & 1 & 2 & 34 & 1 & 2 & 3 & 4 & 1 & 2 & 3 & 4 \\
\hline $\begin{array}{l}\text { Memperhatikan/mendengar } \\
\text { kan penjelasan dosen/ teman }\end{array}$ & & & $\sqrt{ }$ & & & $\sqrt{ }$ & & & $\sqrt{ }$ & & & & & $\sqrt{ }$ \\
\hline Mengidentifikasi masalah & & & $\sqrt{ }$ & & & $\sqrt{ }$ & & & $\sqrt{ }$ & & & & $\sqrt{ }$ & \\
\hline Mencari informasi & & & $\sqrt{ }$ & & & $\sqrt{ }$ & & & $\sqrt{ }$ & & & & & $\sqrt{ }$ \\
\hline $\begin{array}{l}\text { Melibatkan diri dalam } \\
\text { Diskusi }\end{array}$ & & & $\sqrt{ }$ & & & $\sqrt{ }$ & & & & $\sqrt{ }$ & & & & $\sqrt{ }$ \\
\hline $\begin{array}{l}\text { Bertanya jawab dengan } \\
\text { dosen/teman }\end{array}$ & & & $\sqrt{ }$ & & & $\sqrt{ }$ & & & & $\sqrt{ }$ & & & & $\sqrt{ }$ \\
\hline Mengajukan hipotesis & & $\sqrt{ }$ & & & & $\sqrt{ }$ & & & $\sqrt{ }$ & & & & $\sqrt{ }$ & \\
\hline $\begin{array}{l}\text { Berkomentar atau } \\
\text { menanggapi presentasi }\end{array}$ & & & $\sqrt{ }$ & & & $\sqrt{ }$ & & & & $\sqrt{ }$ & & & & $\sqrt{ }$ \\
\hline $\begin{array}{l}\text { Melakukan pembuktian } \\
\text { hipotesis }\end{array}$ & & & $\sqrt{ }$ & & & $\sqrt{ }$ & & & & $\sqrt{ }$ & & & & $\sqrt{ }$ \\
\hline $\begin{array}{l}\text { Melibatkan diri dalam } \\
\text { menyimpulkan hasil diskusi }\end{array}$ & & & $\sqrt{ }$ & & & $\sqrt{ }$ & & & & $\sqrt{ }$ & & & & $\sqrt{ }$ \\
\hline Persentase & & & 100 & & & & & & & & & & & \\
\hline
\end{tabular}

Berdasarkan tabel hasil pengamatan aktivitas peserta didik selama proses pembelajaran berlangsung dengan menggunakan Problem Based Learning yang diterapkan pada 20 mahasiswa yang menjadi sampel dalam penelitian ini maka didapatkan persentase dari aktivitas peserta didik sebesar $83,33 \%$ pada pertemuan pertama dan $91,66 \%$ pada pertemuan kedua sehingga 
menunjukkan peningkatan aktivitas peserta didik dari pertemuan pertama dan pertemuan kedua dalam proses pembelajaran dengan menggunakan model Problem Based learning. Peningkatan aktivitas dapat dilihat dari aspek-aspek yang menjadi focus pengamatan dari pengamat 1 dan pengamat 2 yakni pada aktivitas memperhatikan/mendengar penjelasan dosen/teman didapatkan persentase $75 \%$ pada pertemuan pertama dan $87,5 \%$ pada pertemuan kedua, pada aktivitas mencari informasi didapatkan persentase $75 \%$ pada pertemuan pertama dan $87,5 \%$ pada pertemuan kedua, pada aktivitas melibatkan diri dalam diskusi didapatkan persentase $75 \%$ pada pertemuan pertama dan $87,5 \%$ pada pertemuan kedua, pada aktivitas mengajukan hipotesis didapatkan persentase $62,5 \%$ pada pertemuan pertama dan $87,5 \%$ pada pertemuan kedua, pada aktivitas melakukan pembuktian didapatkan persentase $62,5 \%$ pada pertemuan pertama dan $87,5 \%$ pada pertemuan kedua.

Peningkatan aktivitas peserta didik ini terjadi karena pada pertemuan pertama peserta didik belum terbiasa dengan Problem Based Learning yang mana pada Problem Based Learning mengharuskan peserta didik untuk memecahkan masalah dengan membuat hipotesis berdasarkan masalah yang telah mereka identifikasi kemudian melakukan pembuktian terhadap hipotesis yang telah mereka buat sendiri. sementara pada pertemuan kedua peserta didik sudah lebih terbiasa dengan pembelajaran PBL sehingga aktivitas peserta didik meningkat. Hal ini sesuai dengan hasil penelitian sebelumnya yang menyatakan bahwa penerapan model Problem Based Learning dapat meningkatkan aktivitas keterampilan dan ketercapaian kompetensi siswa (Hilmi. 2015; Janah. 2018; Wasonowati. 2014)

\section{PENUTUP}

Berdasarkan hasil penelitian dan analisis data maka dapat disimpulkan bahwa Problem Based Learning efektif digunakan untuk meningkatkan aktifitas peserta didik dalam pembelajaran kimia pada materi elektrolit dan Non Elektrolit.

\section{DAFTAR PUSTAKA}

Aldianur R, dkk. 2020. Model Talking Stick Pada Pembelajaran Materi Koloid Meningkatkan Hasil Belajar dan Aktivitas Peserta Didik. Jurnal Pendidikan Kimia Indonesia. Vol 4 (2).

Apriliana, D, A, N., \& Diarta, I. M. 2016. Implementasi Problem Based Learning (PBL) dengan Media Mind Mapping Terhadap Kemampuan Pemecahan Masalah Siswa Kelas VII SMP N 2 Megwi Bandung. Jurnal Santiaji Pendidikan, Vol. 6 (1).

Ariyanti, P., dkk. 2015, Penerapan Problem Based Learning (PBL) Dengan Penilaian Portofolio Untuk Meningkatkan Keaktifan Dan Prestasi Belajar Pada Materi Stoikiometri Di SMA N 2 Surakarta Tahun Ajaran 2013/2014. Jurnal Pendidikan Kimia, Vol. 4 (3).

Dewi, J, M, N., dkk. 2017. Pengaruh Model Pembelajaran Problem Based Learning Berbantuan Media Audio Visual Animasi Terhadap Hasil Belajar IPA. Jurnal PGSD Universitas Pendidikan Ganesha, Vol. 5 (2). 
Efendhi, dkk 2014. Pengembangan Bahan Ajar Buku Berjendela Sebagai Pendukung Implementasi Pembelajaran Berbasis Scientific Approach Pada materi Jurnal Khusus. Jurnal Pendidikan Akuntansi. Vol. 2 (1).

Hartoto, T (2016). Model Pembelajaran Kooperatif Tipe Group Investigation (GI) Untuk Meningkatan Aktivitas dan Hasil Belajar Sejarah. Jurnal HISTORIA. Vol. 4 (2).

Hilmi, M., dkk. 2015. Penerapan Model Problem Based Learning Untuk Meningkatkan Aktivitas dan Ketercapaian Kompetensi Siswa. Juornal Chemistry In Education. Vol. 4 (2).

Indayatmi. 2017. Peningkatan Hasil Belajar Kimia Melalui Model Chemisong Pada Peserta Didik Kimia Analisis. Jurnal Edusains, Vol. 9 (1).

Langit, D, S., dkk. 2018. Peningkatan Motivasi Belajar Tematik Menggunakan Model Problem Based Learning Berbantuan Permainan Ular Tangga Pada Siswa Kelas IV. Jurnal Pendidikan Berkarakter, Vol. 1 (1).

Pane, A., \& Muhammad D.D. 2017.Belajar dan Pembelajaran. Jurnal Kajian Ilmu-ilmu Keislaman, Vol 3 (2).

Sutarno, E., \& Mukhidin. (2013). Pengembangan Model Pembelajaran Berbasis Multimedia Interaktif Pengukuran Untuk Meningkatkan Hasil Dan Kemandirian Belajar Siswa Smp Di Kota Bandung. Jurnal Pendidikan Teknologi Dan Kejuruan. Vol. 21 (3).

Sudjana. 2005. Metode Statistika. Bandung: Tarsito.

Sumarni, S., Bimo, B.S., \& Ahchmad, R.S. (2017). Pengaruh Model Pembelajaran Inkuiri Terbimbing Terhadap Hasil Belajar Kognitif Peserta Didik di SMA Negeri 01 Manokwari. Jurnal Nalar Pendidikan. Vol. 5 (1).

Janah.M. C., Widodo. A. T., Kasmui (2018). Pengaruh Model Problem Based Learning Terhadap Hasil Belajar Dan Keterampilan Proses Sains. Jurnal Inovasi Pendidikan Kimia. Vol.12 (1).

Jayadiningrat, M. G., \& Ati, E. K. (2018). Peningkatan Keterampilan Memecahkan Masalah Melalui Model Pembelajaran Problem Based Learning (PBL) Pada Mata Pelajaran Kimia. Jurnal Pendidikan Kimia Indonesia.Vol. 2 (1).

Trianto. (2009). Mendesain Model Pembelajaran Inovatif-Progresif. Jakarta: Kencana.

Yusuf, R (2009). Landasan Pendidikan. Medan: CV. Perdana Mulia Sarana.

Wasonowati. R. R.T., Redjeki. T., Ariani. S. R. D. (2014). Penerapan Model Problem Based Learning (PBL) Pada Pembelajaran Hukum - Hukum Dasar Kimia Ditinjau Dari Aktivitas 
Dan Hasil Belajar Siswa Kelas X Ipa SMA Negeri 2 Surakarta Tahun Pelajaran 2013/2014. Jurnal Pendidikan Kimia. Vol. 3 (3).

Widaningsih, I. (2018). Strategi dan Inovasi Pembelajaran Bahasa Indonesia di Era Revolusi Industri 4,0. : Uwais Inspirasi Indonesia. 